\title{
The influence of organizational social responsibility on involvement behavior in community sport membership associations
}

\author{
Katie Misener $^{1}$ () | Kristen Morrison ${ }^{1}$ | Micheal Shier ${ }^{2}$ | \\ Kathy Babiak ${ }^{3}$
}

${ }^{1}$ University of Waterloo, Waterloo, Ontario, Canada

${ }^{2}$ University of Toronto, Toronto, Ontario, Canada

${ }^{3}$ University of Michigan, Ann Arbor, Michigan

\section{Correspondence}

Katie Misener, Department of Recreation and Leisure Studies, University of Waterloo, 200 University Ave. W., Waterloo, ON, N2L 3G1, Canada. Email: k.misener@uwaterloo.ca

\begin{abstract}
Membership-based associations are critical to their local communities and the overall social impact of the nonprofit sector. This study examines how organizational social responsibility within nonprofit membership associations influences positive member involvement behaviors, including volunteering, speaking positively about the club, and member loyalty. Self-administered online questionnaires were completed by 735 members within seven grassroots membership associations in Ontario, Canada offering community-based sport programs. Results show that members are somewhat aware of and felt positively about their organization's socially responsible efforts. Awareness of these efforts had a positive direct effect on the involvement behaviors of members, including intention to stay involved with their club and speaking positively about their club to others (i.e., word of mouth). Members' level of social consciousness was found to have a positive direct effect on word of mouth. Furthermore, members' positive evaluation of sport clubs' socially responsible initiatives was found to partially mediate the positive relationship between social consciousness and involvement behavior, as well as partially mediate the positive relationship between awareness of those efforts and involvement behavior. Results of this research provide grassroots membership
\end{abstract}


associations with an in-depth understanding of how their organization's efforts toward social responsibility influence member perceptions and behaviors, which may help them focus their efforts and more effectively manage their social change agenda moving forward.

\section{K E Y W O R D S}

community, member behavior, membership association, social responsibility, sport

\section{1 | INTRODUCTION}

Membership-based nonprofit associations play a central role in strengthening local communities (Doherty, Misener, \& Cuskelly, 2014; Hager, Juaneda-Ayensa, Nogueira, Pstross, \& Smith, 2016; Tschirhart \& Gazley, 2014). One form of membership association, which is prominent in communities around the world, is community sport organizations (CSOs). These member-based organizations operate at a local level and provide pathways for children, youth, and adults to take part in a range of sport participation opportunities (Sharpe, 2006). CSOs provide an important structure that enables individuals and families to engage in organized, volunteer-run sport (Doherty et al., 2014). Given that sport and recreation represents one of the largest subsectors of nonprofit and voluntary organizations in many Western countries (Hall et al., 2005), this is a vital context for nonprofit studies.

In addition to providing sport services, which represent the primary mandate for CSOs, these membership associations are also taking on other activities and initiatives that extend their role in local communities and contribution to society (Robertson, Eime, \& Westerbeek, 2018). Many of these initiatives can be conceptualized within a broader framing of "social responsibility," which refers to ethical practices and a more generalized concern for the community beyond an organization's narrow mandate and which is not required by law (Babiak \& Wolfe, 2013; Carroll, 1979; Persson, 2008). While corporate social responsibility (CSR) among commercial sector organizations has become an important focus within management research in the past few decades (e.g., Weyzig, 2009), studies investigating the practice of social responsibility (SR) within nonprofit organizations are much less prevalent (Andreini, Pedeliento, \& Signori, 2014; Morris, 2013; Persson, 2008; Zeimers, Anagnostopoulos, Zintz, \& Willem, 2019). This may be partly because nonprofit organizations are inherently viewed as being socially responsible by virtue of providing a "social good" or service to society. However, SR embodies a broader philosophy of impact by and through an organization's discretionary activities (Carroll, 1979, 1999) and requires organizations across all sectors to ensure that the totality of their actions are socially responsible and not just their primary program/area of interest (Vidal, Torres, Guix, \& Rodríguez, 2005). Indeed, nonprofit organizations can be active agents of SR rather than merely recipients of corporate goodwill (Lee \& Babiak, 2017; Pope, Bromley, Lim, \& Meyer, 2018).

CSOs depend on the involvement of their members (participants and volunteers) for organizational sustainability given that they primarily rely on member-paid fees for revenue and rely almost exclusively on volunteers for their administrative and operational functions (Doherty et al., 2014). Given the growing competition and commercialization within the member-based community sport context (Wicker \& Breuer, 2011), engaging in new organizational practices 
that focus on the club's contribution to the community in addition to sport service provision may not only benefit the community in which the club operates but may also provide important benefits to a sport club, such as enhanced stakeholder perceptions, increased participation numbers, and enhanced loyalty and commitment among members (Morrison, Misener, \& Mock, 2018). Furthermore, knowing whether stakeholders are aware of, and have a positive response to, the SR efforts of an organization is a critical aspect of assessing the impact of such efforts (Sen, Bhattacharya, \& Korschun, 2006; Walker \& Heere, 2011). Therefore, a greater understanding of the socially oriented, discretionary activities of these membership associations and their impact on key constituents is needed in order to ensure that these actions generate maximal impact for the organization and the community.

This research is part of a larger project examining the SR efforts of nonprofit CSOs. Prior exploratory phases of the research program involved focus groups with boards of directors of CSOs in Canada (Misener \& Babiak, 2015). That previous research demonstrated that these local clubs are engaging in socially oriented efforts that address a range of issues, including social inclusion, poverty reduction, environmental preservation, and advocacy for mental health support (Misener \& Babiak, 2015). For example, some clubs have implemented environmental action days in their communities, whereas other clubs have organized food or toy drives to support those in need. Given that participation in community sport requires a significant investment of time, money, and effort, this context offers a unique place of influence in people's lives, shaping their behavior and experience of community. Previous research also showed that clubs approached SR in diverse ways and that CSO efforts to integrate SR into the club's mandate and strategy vary from highly strategic to ad-hoc efforts that were viewed as "the right thing to do" but did not serve a strategic purpose for the clubs (Misener \& Babiak, 2015). In all cases, clubs expressed that they had "freedom" to participate in socially responsible efforts of their choosing, based on their available resources and capacity (e.g., human or financial), and made decisions as a board as to which initiatives to support (Misener \& Babiak, 2015). However, research has indicated that clubs lack a clear understanding of whether their members (i.e., primary stakeholders) were aware of their club's socially responsible efforts and whether members held positive feelings about these initiatives (i.e., affective evaluation). Furthermore, there remains a gap in knowledge regarding whether these social efforts had any impact on their members' involvement in and behaviors toward the club.

Therefore, the purpose of this study was to examine the awareness and impact of SR for CSO members. To address this purpose, the research is guided by two objectives:

1. To examine whether awareness of social responsibility and affective evaluation predict member involvement behavior.

2. To examine whether affective evaluation mediates the relationship between awareness and member involvement behavior.

\section{2 | LITERATURE REVIEW}

\subsection{Positive member involvement behaviors}

In the membership association context, understanding the link between organizational activities and behavioral outcomes is critical. In particular, the sustainability of membership 
associations is highly dependent on the voluntary actions and commitment of their members (Gross \& Rottler, 2018; Paswan \& Troy, 2004). It is thus important for nonprofits to engage in innovative approaches to strengthen the relationships between their members and the organization. A recent study by Pressgrove and McKeever (2016) examined relationship cultivation strategies of nonprofits and their members. They explored one particular aspect-member perceptions of stewardship (i.e., the responsible management of resources). Their findings showed that member perceptions of effective stewardship led to positive behavioral outcomes such as commitment, satisfaction, and trust, and these were influenced by discrete member characteristics such as level of involvement and income. These researchers found that, together, these factors can lead to loyalty, which is one of the foundational attitudinal variables in relationship maintenance. Other research has identified that social and task norms among member-based committees may influence individual performance and behavior such as attendance, effort, and intention to stay in a volunteer role (Doherty, Patterson, \& Van Bussel, 2004; Hoye, 2007). Furthermore, when volunteer members identify closely with the actions of their organization, they are more likely to have high prosocial behaviors, commitment, and satisfaction (Tidwell, 2005).

Another relevant prosocial behavior within the membership association context is the notion of a member speaking favorably about an organization to others, which is generally termed "word of mouth" (Lee, Kim, \& Koo, 2016). These actions may be one manifestation derived from positive identification with an organization (cf. Kim, James, \& Kim, 2013). As one experiences a positive connection with an organization and desires to share this experience with others, they demonstrate a positive attachment with the organization, which can serve an important marketing function (Gross \& Rottler, 2018). Many small nonprofit organizations do not have the resources for traditional marketing or media; thus, positive word of mouth and referrals are an important influence on member acquisition, donor loyalty, and organizational reputation building (Williams \& Buttle, 2013). Positive word of mouth can emulate from the services provided, networking practices, strategic alliances, the volunteers/ officers themselves, and other communication practices (Thomas, Mullen, \& Fraedrich, 2011; Williams \& Buttle, 2013). Indeed, given that SR offers a relationship-building activity within organizations and has an indirect influence on positive word-of-mouth communication (Waters \& Ott, 2014), nonprofit organizations may be able to build their reputation, organizational value, and stakeholder loyalty through the communication channels of their members.

In the CSO context, effective management requires significant attention to ensuring that members (participants and volunteers) are retained. For example, research in the community sport context has long identified volunteer retention as a fundamental challenge for all CSOs, noting that intention to stay is dependent on effective human resource management practices such as clear roles and expectations, training, and recognition (Cuskelly, Taylor, Hoye, \& Darcy, 2006). Recent research has also demonstrated that the value orientation of a CSO toward helping others in the community may also play an important role in whether people continue their affiliation with that club (Misener \& Babiak, 2015). Preventing any loss of volunteers or members offers important benefits for the CSO, including efficiency; enhanced focus on service delivery; and financial benefit, which can prevent increases in member dues (Ringuet-Riot, Cuskelly, Auld, \& Zakus, 2014). Thus, positive appraisal of the club from others (i.e., word of mouth) may offer CSOs an important mechanism for strengthening their relationship with members and ensuring positive attachment with the organization. 


\section{2 | Awareness of SR}

Much of the research examining the outcomes of SR has occurred in the corporate context and has demonstrated important links to purchasing behavior, consumption of a company's products, brand loyalty, and attractiveness to potential employees (Sen et al., 2006). Based on their research on SR in commercial sport, Walker and Heere (2011) note that behavior is context-specific, and thus, researchers should narrow their investigation to particular behavioral patterns found in a given context or type of organization. As such, the unique context of nonprofit member-based sport merits further investigation of the influence of SR initiatives on members given the high degree of involvement, investment of time and money by families, and trend toward value-driven programming (Doherty \& Misener, 2008; True Sport Foundation, 2016). The characteristics of this membership environment therefore influence how these organizations are managed and their ultimate sustainability. While emerging research highlights the relevance of SR as a growing phenomenon within the nonprofit domain (e.g., Andreini et al., 2014; Lin-Hi, Hörisch, \& Blumberg, 2015; Pope et al., 2018; Zeimers et al., 2019), little is known about how these activities influence and shape a member's behavior toward a nonprofit organization.

Understanding whether stakeholders are aware of their organization's socially responsible efforts is a critical aspect of assessing the impact of these actions (Lee \& Babiak, 2017; Sen et al., 2006). Much of the previous research on SR implicitly assumed that individuals would naturally be aware of an organization's social initiatives if they interacted with an organization (Bruner, Hensel, \& James, 2005). Research has noted that awareness of an organization's SR among key stakeholders is actually a key stumbling block to attaining full organizational benefits such as intention to purchase/donate, enhanced brand image and identity, and feelings of organizational connectedness and loyalty (Du, Bhattacharya, \& Sen, 2007; Lee \& Babiak, 2017; Sen et al., 2006). Notably, research shows that stakeholders often have low awareness of an organization's socially responsible efforts (Du, Bhattacharya, \& Sen, 2010; Sen et al., 2006), and this lack of awareness may be linked to poor corporate communication efforts of CSR (Du et al., 2010; Morsing \& Schultz, 2006).

In critiquing the attitude formation research, Walker and Heere (2011) note that "most attitudinal scales tend to focus on the affective part of the attitude, rather than the awareness of social variables" (p. 156). They further note that awareness is often implicitly assumed rather than measured as an empirical construct. Walker and Heere's (2011) Consumer Attitudes toward Responsible Entities in Sport (CARES) model incorporates cognitive awareness as a precursor to determining stakeholder response to SR given that the awareness of a social variable (such as CSR) precedes the development of positive (affective) associations of that variable (Funk \& James, 2004; Zajonc, 2001), and both may influence behavior (Kumar, Lee, \& Kim, 2009). In the context of spectator sport, Morrison et al. (2018) found that the higher a sport spectator's level of awareness of CSR initiatives, the greater his or her media consumption of that organization. The researchers conducted further mediation analyses using team identification as a variable and found that the association between awareness and media consumption was partially explained by links through team identification (Morrison et al., 2018). Thus, explicitly examining member awareness of SR may help us better understand member responsiveness to the club's discretionary actions (cf. Morrison et al., 2018). Drawing on this literature and recognizing that, to date, there has been no research examining member awareness of SR in the CSO context, our first hypothesis is as follows: 
H1 Higher levels of awareness of community sport club socially responsible activities among members will result in higher levels of positive member involvement behaviors (i.e., word of mouth, volunteering, and intentions to stay).

\section{3 | Affective evaluation}

Positive feelings toward an organization's actions (i.e., affective evaluation) are critical in determining any behavioral response (Bhattacharya \& Sen, 2004; Diddi \& Niehm, 2016; Du et al., 2010; Ross, Stutts, \& Patterson, 1990; Walker \& Heere, 2011). Research demonstrates that affective evaluation (e.g., feelings and perceptions about an activity) will influence the desirability of CSR and willingness of consumers to respond positively (Bhattacharya \& Sen, 2004; Ross et al., 1990). In turn, behavior (e.g., participation/involvement, willingness to pay, speaking favorably about an organization) is derived from the combined influences of awareness and affect. Indeed, awareness alone is a weak antecedent of behavior, and thus, affective evaluation plays a central role in the potential outcomes of CSR (Du et al., 2007; Sen et al., 2006). Walker and Heere's (2011) CARES framework offers a valuable way to understand the factors that explain the potential impact of SR on stakeholders in the sport context, given the diverse extant literature on CSR outcomes (e.g., Aguinis \& Glavas, 2012). Walker and Heere (2011) found that it is the causal link between CSR awareness and affective evaluation that led to spectator purchase behavior. Morrison et al. (2018) also found a direct positive effect of affective evaluation of CSR initiatives on repeat purchasing, merchandise consumption, media consumption, and word of mouth. Based on these findings, we propose the following hypothesis:

H2 The positive effects of awareness and social consciousness on club member involvement behaviors will be mediated by higher levels of positive affective evaluation toward member engagement with socially responsible activities.

\section{3 | METHODS}

Utilizing a quantitative cross-sectional research design, a purposive sample of sport club members in Ontario, Canada were surveyed. The survey was emailed to members of seven CSOs $(N=6,574)$ whose boards had previously participated in an exploratory qualitative study conducted by the researchers and, during that study, had indicated that their club was involved in at least three socially responsible initiatives per year (Misener \& Babiak, 2015). Beyond these inclusion criteria for the participating sport clubs, the only other inclusion criterion for the individual survey research participants was that they were currently listed as members of one of the seven CSOs. This study received ethics certification from the Principal Investigator's institutional research ethics board.

\section{1 | Procedures}

Survey measures were compiled from a review of the previously identified literature and were adapted to meet the needs of this study sample/context. Given the novel focus on SR in CSOs, the draft instrument was circulated to an expert panel of five researchers who have extensively 
published work in the areas of nonprofit community sport and/or CSR in sport. The panel was asked to provide feedback about the wording of the instructions to participants and the actual items of each of the distinct measures, with a specific focus on their clarity and conciseness. In order to differentiate SR from a sport club's core programming, it was determined that an introductory line for the survey would be included, stating that "While sport itself may be good for a community, we are interested in the ethical and charitable actions the club takes above and beyond its own sport programs." Furthermore, the panel was asked to comment on whether the items listed in each construct represented valid indicators of that construct (i.e., face validity) and whether there were any items missing or any that did not belong, with a focus on the community sport context. After receiving feedback from the expert panel, minor modifications to the items were made, with unclear items reworded for clarification and redundant items removed. Following the refinement of the draft survey instrument, a pilot survey was sent to seven CSO members to solicit feedback on the time required to complete the survey, as well as the clarity and ease of completion. These results were not included in the final study, and results from the pilot test indicated that no further modification was needed.

The final study was sent to the presidents or their representatives of each of the seven CSOs who agreed to distribute an email directly to their current club members, inviting them to participate in the study. In cases where members were under the age of 18, parents were invited to participate. The email included a link to the online survey on a secure SSL encrypted website. Per Dillman's (2007) recommendations, the CSOs distributed reminder emails 1 and 2 weeks following the initial invitation. A total of 735 participants across the seven CSOs participated in the study, resulting in an $11.18 \%$ response rate. This response rate raises concerns about nonresponse bias (Hager, 2013, 2014), resulting in the need to use caution when interpreting the results to the general population of members of CSOs. For example, it is likely that those more committed to their club's SR activities were more inclined to complete the survey, leading to more positive results for the measured independent variables of affective evaluation and awareness of SR. This limitation is discussed in further detail below in the Results and Discussion sections.

\section{2 | Measures}

The three dependent variables included word of mouth, intention to stay with the club, and amount of volunteering, all of which represent positive member behaviors for club engagement as previously described in the literature review. The independent variables included the respondent's awareness of socially responsible activities undertaken by the club and his or her positive affect toward his or her club's engagement in socially responsible activities. Other independent variables included the member's general level of social consciousness along with demographic variables that may act as alternative explanations for the direct and indirect (i.e., through positive affective evaluation toward a club's involvement in socially responsible activities) effects of awareness and social consciousness on each of the positive member behavior variables.

\subsection{1 | Word of mouth}

Word of mouth refers to the active promotion of the club to people who are not members. This construct was operationalized as a five-item measure developed from the literature on 
word of mouth in sport volunteering contexts (Lee et al., 2016) and nonprofit cause-related marketing (Thomas et al., 2011). In the current study, participants were asked to rate the following items on a 7-point Likert-type scale ( $0=$ strongly disagree to $6=$ strongly agree): (1) "I encourage my friends to join this club," (2) "I like providing information about my club to people," (3) "I tell others about my club," (4) "I speak positively to others about my club," and (5) "I recommend my club to people who seek my advice." The current study found adequate reliability $(\alpha=.91)$. Furthermore, a confirmatory factor analysis (CFA) was used to evaluate construct validity of the word-of-mouth scale. Model fit statistics (including the Chi-Squared test of model fit, the Comparative Fit Index (CFI), the Tucker-Lewis Index (TLI), and the Root Mean Square Error of Approximation (RMSEA)) were assessed to determine adequacy of model fit and, subsequently, the validity of the measure (Kline, 2011). The model demonstrated acceptable fit indices: $\chi^{2}(4)=7.03, p=.1342$, CFI $=0.999$, TLI $=0.997$, and RMSEA $=0.032$.

\subsection{2 | Intention to stay}

Intention to stay refers to a members' loyalty and level of involvement in the club and was measured using four items adapted from Gruen, Summers, and Acito (2000). Participants were asked to rate their agreement with the following four statements using a 7-point Likert-type scale ( $0=$ strongly disagree to $6=$ strongly agree): (1) "I intend to remain as a member of this organization," (2) "I am willing to put in a great deal of effort to help this club to succeed," (3) "I feel a great deal of loyalty to this club," and (4) "I am willing to engage in more club activities." The four items representing intention to stay had satisfactory reliability $(\alpha=.88)$. The variable also demonstrated sufficient construct validity, represented by the following fit indices: $\chi^{2}(1)=4.51, p=.0336, \mathrm{CFI}=0.997$, TLI $=0.984$, RMSEA $=0.069$.

\subsection{3 | Volunteer hours}

The number of volunteer hours was assessed with a continuous variable of actual number of hours in which a respondent volunteered with the sport club. An open-ended question asked participants to indicate approximately how many hours per week they volunteered for their club during the sport season.

\subsection{4 | Awareness of SR}

A five-item scale from Walker and Kent (2013) was adapted for this study to reflect the community sport context and was used to measure awareness of SR by club members. Participants were asked to rate their agreement with the following five statements using a 7-point Likerttype scale ( 0 = strongly disagree to $6=$ strongly agree): (1) "I know how the club helps the community above and beyond providing sport services," (2) "I am informed about the efforts my club takes to be socially responsible," (3) "I believe the club is involved in community-minded initiatives in addition to sport programs," (4) "I am aware that the club participates in activities which support all community members rather than those who are only involved in our club," and (5) "I can see how my club is actively engaged in addressing the needs of others in our 
community." The scale had adequate reliability with this study sample $(\alpha=.93)$, and a CFA demonstrated acceptable construct validity: $\chi^{2}(4)=11.52, p=.0213$, CFI $=0.997$, TLI $=0.994$, RMSEA $=0.0052$.

\subsection{5 | Affective evaluation}

In the context of this study, affective evaluation refers to how members feel about the SR initiatives that the club undertakes. A five-item scale, which was adapted from Walker and Heere (2011) to reflect the community sport context, was utilized to measure affective evaluation of socially responsible activities. Participants were asked to rate their agreement with the following five statements using a 7-point Likert-type scale ( $0=$ strongly disagree to $6=$ strongly agree): (1) "I feel good about the club because of all the activities they do to benefit the community above and beyond sport," (2) "Part of the reason I like this club is because of what they do for others in need," (3) "The club's commitment to helping others gives me a positive feeling about this club," (4) "I feel disappointed when the club doesn't care for our community outside of sport programs" (reverse coded), and (5) "I like it when our club engages in actions that address a societal issue beyond sport." The scale demonstrated adequate reliability ( $\alpha=.83$ ), and a CFA demonstrated acceptable construct validity with the following fit indices: $\chi^{2}(3)=4.59$, $p=.2042$, CFI $=0.999$, TLI $=0.996, \mathrm{SMR}=0.028$.

\subsection{6 | Demographics}

Several demographic variables were included in the analysis. These variables included gender, age, highest level of education achieved, employment status, and level of social consciousness. In addition, the number of years that participants have been involved in their club and the number of roles participants hold in their club were included in the analysis (see Table 1). It is quite common that individuals have multiple roles with community sport clubs (e.g., parent and volunteer). Social consciousness refers to the tendency to behave in socially responsible ways (Webster, 1975). A participant's perceived level of social consciousness has been positively associated with the awareness of SR initiatives (Walker \& Kent, 2013); as such, we expect that social consciousness will be positively related to the awareness of SR initiatives and, as a result, needs to be controlled for in our analysis. The variable was assessed by using a single item from Walker and Kent (2013), who adapted it from Lichtenstein, Drumwright, and Braig (2004), that asked participants to rate their agreement with the following statement using a 7-point Likert-type scale $(0=$ strongly disagree to $6=$ strongly agree): "I consider myself to be a socially conscious person." Furthermore, previous research on volunteering in sport has demonstrated that males are more likely to volunteer in sport settings, as are individuals aged 35-44 and those with higher levels of education (Doherty, 2005). While not specific to the sport context, volunteers who are not in the labor force, such as retirees and homemakers, contribute more hours on average (Sinha, 2015). However, no research exists among members of CSOs that identifies an association between the other demographic variables and perceptions of SR (awareness and affective evaluation). Therefore, our hypotheses for each demographic characteristic on perceptions of SR remained open. 
TA B LE 1 Descriptive statistics of participant demographic variables (for which data are available)

$\begin{array}{ccc}\text { Variable } & \text { Frequency (\%) } & \text { Mean (SD) } \\ \text { Age (years) } & & 42.0(9.0) \\ 14-25 & 41(7.1) & \\ 26-35 & 73(11.5) \\ 36-45 & 283(43.6) \\ 46-55 & 224(35.1) \\ 56-65 & 17(2.7)\end{array}$

Gender

Male

$220(33.2)$

Female

$442(66.8)$

Education

Less than high school

High school diploma

College/university/trade school

$387(58.5)$

Graduate degree

$194(29.3)$

Employment

Working

$552(83.5)$

Not working

$109(16.5)$

Years involved in the club

0-5

$430(65.5)$

6-10

$174(26.6)$

$11+$

$52(7.9)$

Volunteer hours (hr/week)

Zero (0)

$411(62.5)$

1-4

$165(24.9)$

4-9

$46(7.1)$

10-14

$17(2.5)$

15-19

4 (0.6)

$20+$

$16(2.4)$

Social consciousness ${ }^{\mathrm{a}}$

$4.75(.9)$

Role in club ${ }^{b}$

Volunteer board member

$17(2.0)$

Parent of member

$471(44.2)$

Club member

$138(16.4)$

Volunteer with honorarium

$6(0.7)$

General volunteer

$121(14.4)$

Volunteer coach

$118(14.0)$

Volunteer manager

$33(3.9)$

Other

$36(4.3)$

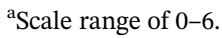

${ }^{\mathrm{b}}$ Participants could select all roles that apply to them. ${ }^{*} p<.05 ;{ }^{* *} p<.01 ;{ }^{* * *} p<.001$. 


\section{3 | Data analysis}

Structural equation modeling (SEM), with full information maximum likelihood estimation techniques, was utilized as the analytical method to address missing data and was supported by the MPlus statistical software package (Muthén \& Muthén, 1998). SEM was utilized because it allows for the simultaneous estimation of multiple dependent variables (for which there are three in this study), along with assessing direct and indirect effects of latent variables on multiple outcomes (i.e., the direct and indirect effects [through affective evaluation] of awareness of socially responsible activities on each of the three positive club member behaviors assessed in this study) (Kline, 2011). Furthermore, SEM allows for both the simultaneous estimation of the confirmatory and structural models, a necessary requirement given that we are testing relationships with latent variables (Kline, 2011). SEM is also a superior analytical method for the purposes of this study-which aimed to identify the unique effects of various independent variables on multiple related outcome variables-because it allows for the error terms of multiple related dependent variables to correlate. This is a reasonable assumption given that it is likely that there is common unexplained variance among each of the dependent variables because each assesses different aspects of the common construct of positive club member behaviors related to their club participation, involvement, and engagement. Figure 1 provides a diagram of our tested model. Note that demographic variables are not represented in the figure but were included in the analysis.

\section{4 | RESULTS}

Table 1 provides the descriptive statistics for the demographic characteristics of the study sample. Of the respondents, most were female (66.8\%), between 36 and 55 years of age (77.7\%), had completed college/university or trade school (58.5\%), and were employed outside of the home (83.5\%). In addition, most respondents indicated that they had been members of the club for up to 5 years $(65.5 \%)$, did not currently volunteer at the club (62.5\%), and were parents of members

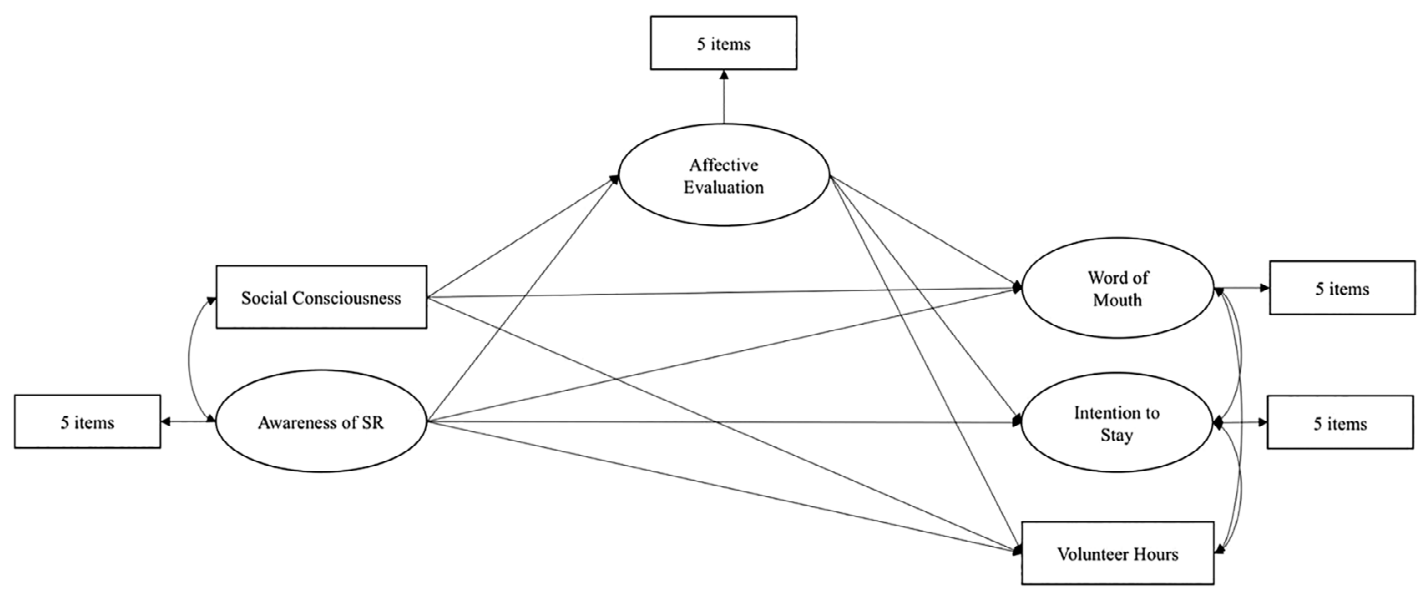

F I G U RE 1 Structural equation model depicting direct and indirect effects (through affective evaluation) of awareness of socially responsible activities on the three positive club member behaviors 
(44.2\%) and/or members themselves (16.4\%). On average, respondents indicated having a moderate to high level of social consciousness $(M=4.75)$. As the representativeness of the sample is not known, the findings should not be generalized to the population of members of CSOs. Furthermore, generalizing is also not appropriate given that the survey was distributed among a small sample of CSOs in one region within one single country context.

Table 2 provides descriptive statistics for awareness of SR, affective evaluation, intent to stay, word of mouth, and volunteer hours. On average, respondents indicated that they were somewhat aware of $(M=3.40)$ or held a positive affective evaluation about $(M=3.72)$ their club's SR activities. However, respondents indicated a moderate to high intention to stay at their current club $(M=4.28)$ and that they typically spoke positively to others about their club $(M=4.66)$. Furthermore, on average, respondents indicated that they volunteered $2.12 \mathrm{hr}$ per week at their club during their sport season.

Table 3 shows the regression results of the structural equation model tested to assess the two hypotheses with respect to whether awareness of SR, social consciousness of members, and

T A B LE 2 Descriptive statistics: Means and standard deviations (for which full data are available) Cronbach alpha coefficient $(\alpha)$ and response ranges of the awareness and affective evaluation of SR and member behaviors

\begin{tabular}{|lllll|} 
Variable & Mean & $\boldsymbol{S D}$ & $\boldsymbol{\alpha}$ & Response range \\
\hline Awareness of SR & 3.40 & 1.39 & .93 & $0-6^{\mathrm{a}}$ \\
\hline Affective evaluation & 3.72 & 0.96 & .83 & $0-6^{\mathrm{a}}$ \\
\hline Intent to stay & 4.28 & 1.17 & .85 & $0-6^{\mathrm{a}}$ \\
\hline Word of mouth & 4.66 & 1.05 & .91 & $0-6^{\mathrm{a}}$ \\
\hline Volunteer hours & 2.12 & 6.54 & - & $0-100$ \\
\hline
\end{tabular}

${ }^{\mathrm{a}}$ Scale range of $0-6$.

${ }^{*} p<.05 ;{ }^{* *} p<.01 ;{ }^{* * *} p<.001$.

T A B LE 3 Multivariate regression results for predicting member behaviors with awareness and affective evaluation of SR

$\begin{array}{lll}\text { Intent to stay } & \text { Word of mouth } & \text { Volunteer hours } \\ B & B & B\end{array}$

\begin{tabular}{|c|c|c|c|}
\hline \multicolumn{4}{|l|}{ Predictors entered } \\
\hline \multicolumn{4}{|l|}{ Demographic characteristics } \\
\hline Social consciousness & 0.055 & $0.122^{* *}$ & 0.051 \\
\hline Gender & -0.047 & -0.010 & $-1.319^{*}$ \\
\hline Age & 0.002 & 0.005 & $0.077^{*}$ \\
\hline Education & -0.046 & 0.048 & -0.066 \\
\hline Employment & -0.049 & -0.089 & $-1.963^{* *}$ \\
\hline Years involved & 0.009 & -0.008 & 0.055 \\
\hline Number of roles in club & $0.090^{*}$ & $0.088^{*}$ & $1.094^{* * *}$ \\
\hline Awareness of SR & $0.185^{* * *}$ & $0.185^{* *}$ & 0.209 \\
\hline Affective evaluation & $0.220^{* *}$ & $0.220^{* *}$ & -0.145 \\
\hline$R^{2}$ & 0.299 & 0.230 & 0.061 \\
\hline
\end{tabular}


affective evaluation predict involvement behavior. An acceptable model was determined by the quality of the following fit indices: Chi-Squared test of model fit, the CFI, the TLI, and the RMSEA (Kline, 2011). The multivariate analysis for predicting member behaviors with awareness and affective evaluation of SR in our hypothesized model (i.e., Figure 1) showed acceptable model fit with the following indices: $\chi^{2}(255, N=735)=713.93, p<.0001$, CFI $=0.954$, TLI $=0.940$, RMSEA $=0.049$. The structural model results highlight the direct significant effects of the awareness of SR initiatives and five of the demographic characteristics on positive member behaviors.

As expected based on previous research, males were more likely to volunteer more hours per week than females, as were those between ages 34 and 45 and individuals not employed outside of the home. Findings also suggest that members who held multiple roles in the club were also more likely to volunteer more hours per week. Level of education was not significantly related to number of volunteer hours per week. In addition, gender, age, employment status, level of education, and years involved with the club were not significantly related to awareness or affective evaluation of SR initiatives, word of mouth, or intention to stay. Finally, social consciousness was found to have a statistically significant effect on a member's positive word of mouth about their club.

Our second research question sought to determine whether affective evaluation mediates the relationship between awareness and involvement behavior. This research question is reflected in our second hypothesis, which stated that the positive effects of awareness and social consciousness on club member involvement behaviors will be mediated by higher levels of positive affective evaluation toward member engagement with socially responsible activities. The model results show support for this hypothesis as they illustrate the mediating effects (through the degree of positive affective evaluation among club members) of awareness of a CSO's socially responsible activities and their level of social consciousness on the three dependent variables. Figure 2 provides the unstandardized coefficients for the significant effects from this analysis. Of note, there were no direct or indirect effects (through affective evaluation) of awareness and social consciousness on the extent to which participants volunteered. This is represented in Figure 2 with no arrows or corresponding significant effects between these variables.

Table 4 provides unstandardized coefficients and confidence intervals for the significant direct and indirect effects. The results from Figure 2 and Table 4 show that club members' level of social consciousness has a statistically significant indirect effect on their intention to stay involved with their club that is mediated by members' affective evaluation of their club's role in engaging in socially responsible activities. Of the effect of social consciousness on intention to stay, $50 \%$ is explained by the direct effect (which is not statistically significant), and subsequently, $50 \%$ is explained by the indirect effect, mediated by affective evaluation. The total effect of social consciousness on a club member's intention to stay is statistically significant ( $p=.007)$; however, this statistical significance is explained entirely by the indirect effect. This suggests that, in general, members who are more socially conscious intend to stay longer with their clubs if they have a more positive affective evaluation toward their clubs' involvement in coordinating and undertaking socially responsible activities.

In addition, members' level of social consciousness has a statistically significant positive effect on positive word of mouth about the club among members. The results show that $70 \%$ of this effect is a direct effect between social consciousness and positive word of mouth (which from Table 3 was a statistically significant direct effect), and subsequently, $30 \%$ is a statistically significant indirect effect mediated by higher levels of positive affective evaluation among 


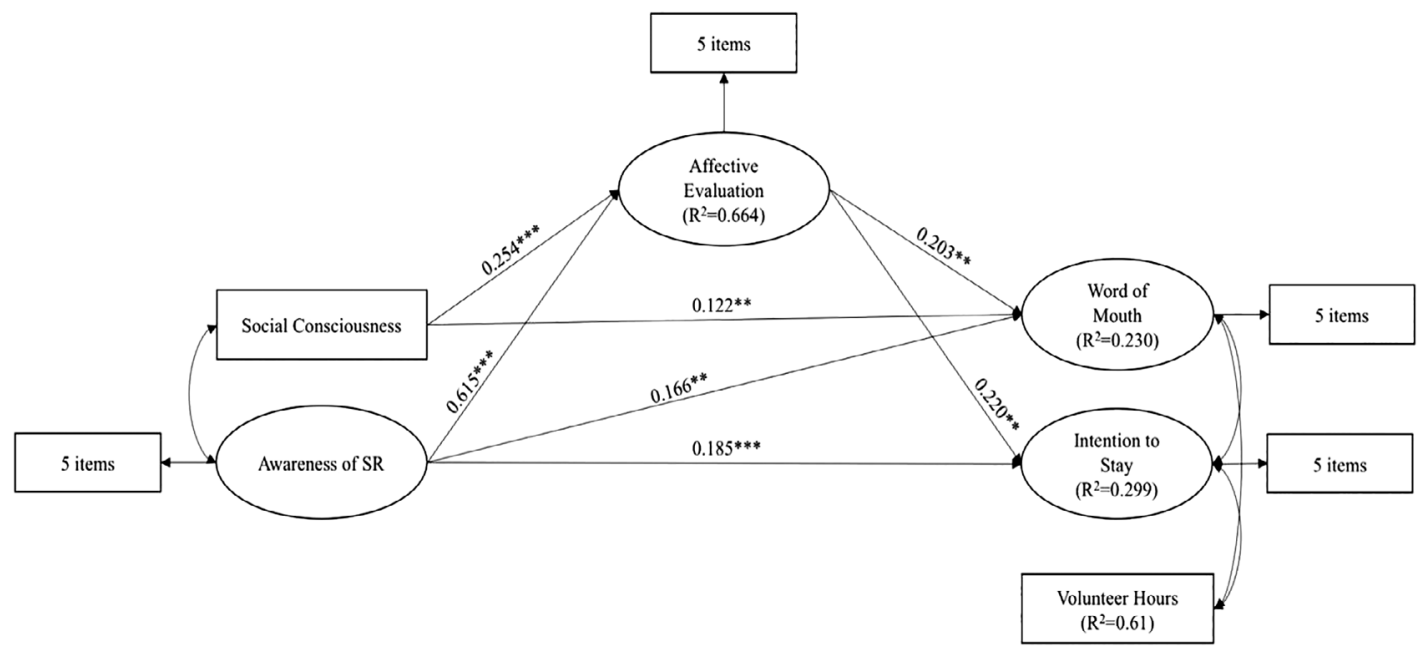

F I G U RE 2 Final model with unstandardized path coefficients. Squares represent measured variables. Values are unstandardized regression weights. Note: ${ }^{*} p<.05,{ }^{* *} p<.01,{ }^{* * *} p<.001$. Model fit: $\chi^{2}$ $(255, N=735)=713.93, p<.001, \mathrm{CFI}=.95, \mathrm{TLI}=.94, \mathrm{RMSEA}=.05$

T A B L E 4 Summary of total, indirect, and direct effects for predicting member behaviors with awareness and affective evaluation of SR

\begin{tabular}{|c|c|c|c|c|}
\hline \multirow{2}{*}{$\begin{array}{l}\text { Outcome variable } \\
\text { Predictor variable: Social consciousness }\end{array}$} & \multicolumn{4}{|c|}{ Intent to stay } \\
\hline & $\boldsymbol{B}$ & Variance (\%) & $\mathbf{B}$ & $95 \%$ CI for $B$ \\
\hline Direct & 0.055 & 50 & 0.055 & -0.026 to 0.136 \\
\hline Total indirect (affective evaluation) & 0.056 & 50 & 0.056 & 0.015 to 0.097 \\
\hline Total & \multicolumn{2}{|l|}{0.111} & 0.111 & 0.038 to 0.184 \\
\hline Predictor variable: Awareness of SR & $B$ & Variance $(\%)$ & $\beta$ & $95 \%$ CI for $B$ \\
\hline Direct & 0.185 & 58 & 0.264 & 0.081 to 0.289 \\
\hline Total indirect (affective evaluation) & 0.136 & 42 & 0.194 & 0.048 to 0.224 \\
\hline Total & \multicolumn{2}{|l|}{0.320} & 0.458 & 0.259 to 0.381 \\
\hline Outcome variable: & \multicolumn{4}{|c|}{ Word of mouth } \\
\hline Predictor variable: Social consciousness & $\boldsymbol{B}$ & Variance (\%) & $\beta$ & $95 \% \mathrm{CI}$ for $B$ \\
\hline Direct & 0.122 & 70 & 0.115 & 0.037 to 0.233 \\
\hline Total indirect (affective evaluation) & 0.052 & 30 & 0.049 & 0.011 to 0.093 \\
\hline Total & 0.173 & & 0.164 & 0.096 to 0.250 \\
\hline Predictor variable: Awareness of SR & $B$ & Variance (\%) & $\beta$ & $95 \%$ CI for $B$ \\
\hline Direct & 0.166 & 57 & 0.255 & 0.057 to 0.274 \\
\hline Total indirect (affective evaluation) & 0.125 & 43 & 0.169 & 0.035 to 0.215 \\
\hline Total & 0.291 & & 0.394 & 0.232 to 0.350 \\
\hline
\end{tabular}

Note: $B$, unstandardized coefficients; $\beta$, standardized coefficients. 
members toward their clubs' engagement in socially responsible activities. The results suggest that members who indicate being more socially conscious will speak more positively about their club but also that the level of positive word of mouth is indirectly affected by a member's positive affective evaluation toward his or her club's involvement in socially responsible activities. No direct or indirect effects were identified between social consciousness and the amount of time respondents spend volunteering with their clubs. Table 4 provides the breakdown of the significant direct and indirect effects (through affective evaluation) of social consciousness and awareness on the outcomes of positive word of mouth and intentions to stay with respondents' clubs.

Furthermore, results from our analysis supported our first hypothesis, which stated that higher levels of awareness of community sport club socially responsible activities among members will result in higher levels of positive member involvement behaviors (i.e., word of mouth, volunteering, and intentions to stay). In particular, as is demonstrated in Table 3, the results from this analysis show that respondents' awareness of their club's socially responsible initiatives has a statistically significant direct effect on members' intention to stay with their club. In addition, as shown in Figure 2 and Table 4, the analysis found that there was a statistically significant indirect effect of awareness of their club's SR activities on members' intention to stay with their club that is mediated by their positive affective evaluation of their club's socially responsible activities. Of this effect, $58 \%$ is explained by the direct effect, and subsequently, $42 \%$ is explained by the indirect effect, mediated by affective evaluation. In addition, awareness of socially responsible activities by club members has a statistically significant direct effect on club members' willingness to speak positively (i.e., word of mouth) about their club. The results also show that there is a statistically significant indirect effect of awareness of club SR activities on members' willingness to speak positive about their club that is mediated by their affective evaluation of their club's role in engaging in socially responsible activities. Of this effect, $57 \%$ is explained by the direct effect, and subsequently, $43 \%$ is explained by the indirect effect, mediated by affective evaluation. Based on these study results, members' awareness of CSOs' SR initiatives have a direct effect on some positive member involvement behavior. However, this effect is amplified by members' affective evaluation toward their club's socially responsible activities.

These results suggest that it is not only important for members to be aware of a club's involvement in socially responsible activities-which, from these findings, can contribute directly to a club members' intention to stay and their positive word of mouth about their club to others-but a members' positive affective evaluation can also amplify these positive club member behaviors. Further explanation of these results and resulting implications for club development are offered in the following Discussion and Implications section.

\section{5 | DISCUSSION AND IMPLICATIONS}

Previously, there has been a gap in knowledge related to how the socially responsible actions of a nonprofit organization, above and beyond its mandate, may influence a member's behavior toward the organization (cf. Lin-Hi et al., 2015). The results of this study support the hypotheses and provide evidence of the influence of socially responsible efforts by grassroots membership associations on the association itself via membership behaviors that support the function and reputation of the CSO. By influencing member behaviors, the overall effect of organizational SR may be a civic spillover where nonprofit organizations benefit from greater involvement of 
members because of members' positive appraisal of the socially responsible actions of the association. This represents a potential mechanism, particularly in the CSO context, for civic engagement and associational behavior, in addition to the community impact that may result from an organization's increased social action in their community above and beyond their traditional mandate.

Similar to previous research on consumer awareness of CSR (Du et al., 2010; Sen et al., 2006), participants in the current study indicated that they were somewhat aware of their club's SR efforts. This level of awareness demonstrates that members are paying attention to the socially responsible actions of their club. However, greater awareness of these efforts may not have been reached as CSOs have yet to demonstrate strategic communication around these initiatives (Misener \& Babiak, 2015). In addition, members held a positive affective evaluation about their club's SR activities. This finding offers new evidence of the multiplicity of roles of sport clubs in society and the approval of members as CSOs expand their reach in the community. These innovative social activities may thus represent a new way of demonstrating valuesbased sport (cf. True Sport Foundation, 2016). The results also demonstrate that it may indeed be important for members to be aware of their club's involvement in socially responsible activities, which can contribute directly to a members' intention to stay and to their engagement in positive word of mouth about the club. In general, a member's positive affective evaluation can also amplify these member behaviors. This finding highlights opportunities for CSOs to leverage their socially responsible efforts into positive internal outcomes via positive involvement behaviors.

While social consciousness was a confounding variable included in the analysis, the results uniquely show that it too appears to be important in promoting positive member behaviors within community sport clubs, and its effect is in part mediated by the affective evaluation of the member for socially responsible activities by the club. Engagement in social consciousnessraising activities could be an important area of development within community sport to engage members and promote positive member behaviors. Further research is needed to develop additional insights about the relationship between social consciousness and club member behavior.

Much like in other voluntary domains, there are increasing pressures facing contemporary membership associations who wrestle with the acquisition and retention of members (Hager et al., 2016). Community sport clubs, much like other membership associations, must navigate growing competition for members, scarce financial resources, increased reporting requirements for government grants, and trends toward privatization and professionalization (Nichols et al., 2005; Sotiriadou \& Wicker, 2013). If growth and even sustainability is desired, decision makers within these organizations must incur added responsibility to strengthen the relationship between the organization and its prime beneficiary: members. As expectations of nonprofit organizations continue to evolve, the strategic relevance of SR may continue to grow as it offers an added dimension of service quality and may strengthen perceptions of an organization's mission (cf. Andreini et al., 2014).

\section{1 | Implications for research}

This study is part of a growing body of research related to "off-the-field" outcomes of community sport (e.g., Misener \& Babiak, 2015; Skinner, Zakus, \& Cowell, 2008; Tonts, 2005) and provides CSOs with a new understanding of how SR is perceived by members and influences member behaviors. Members generally felt positive about what the club did for the community 
"above and beyond" its sport-related programs. It is important to continue to study these efforts in order to encourage affective evaluation, which in turn predicts intention to stay and positive word of mouth. The next steps for future research stemming from this study include a comprehensive examination of the particular organizational capacities that enable these initiatives to be successfully implemented. In many membership contexts, such as community sport, organizations may already work with limited/scarce resources and need to be cognizant that they are not "stretched too thin" by adding extra initiatives (cf. Robertson et al., 2018). It is therefore important to understand the particular resource demands and organizational capacities required for any initiative that exists outside the core mandate of the organization. Further research should also examine the parameters of social change activities in terms of time, commitment, and focus/intentionality to determine whether particular forms of social change activities can be categorized, compared, and linked with particular member behaviors. In addition, linking this phenomenon to other theoretical explanations (e.g., organizational commitment and identity) may offer new ways of understanding how the socially minded actions of a sport organization can influence members and other stakeholders.

These avenues for future research may help to address current limitations of the study. The primary limitation of this study is the low response rate, resulting in the likely nonresponse bias previously discussed. That is, we are unable to determine if respondents generally represented views held in the population of members within these seven clubs. In fact, it is likely that those who were more favorable to the CSO's socially responsible activities were more likely to respond to the survey. As a result, the conclusions made in this study can only be made of the sample of respondents. While these respondents do represent a group of members that participate in CSOs, further research is needed that seeks feedback from members who do not support the SR activities of CSOs. As such, the generalizability of the findings are significantly limited but do provide useful insights at least among a sample of CSO members who are generally aware and have a positive affect toward a CSO's engagement in socially responsible activities.

Furthermore, it is not possible to make comparative conclusions across the different membership roles as there is insufficient data for many of the groups (e.g., volunteer board members or coaches). Further research is needed to better understand the specific perspectives of these individual groups. A further limitation of the study design is that the sample reflects only clubs that engage in socially responsible activities, and thus, we cannot draw comparisons to member behavior in clubs without socially responsible activities. Future research would benefit by using a control group to determine whether these differences exist. Furthermore, the models reported are linear regression models. From a theoretical standpoint, more awareness would always seem to be a benefit. However, further research could be undertaken to determine if there are threshold effects.

\subsection{Implications for practice}

The evidence from this study may help CSO leaders focus their efforts and more effectively leverage their social change agenda into membership behaviors that support the organization while demonstrating leadership in their communities by responding to social needs. Based on the results of the current study, CSO leaders may be able to improve their decision-making related to discretionary club activities. In particular, it is important to increase members' awareness of SR initiatives through social media, regular communications (e.g., newsletters), and regular face-to-face encounters within the club. Promoting awareness within the club, rather than 
perhaps taking social action behind the scenes in board or other small leadership group/team meetings, can be advantageous to fostering pro-club behaviors. Furthermore, members generally felt positive about what the club did for the community above and beyond its sport-related programs. It is therefore important to continue these efforts in order to encourage affective evaluation, which in turn predicts member behaviors such as intention to stay and positive word of mouth. Sport clubs and other member associations such as arts-based organizations may be able to derive further benefit by asking their membership base for suggestions and particular causes to connect with and contribute toward in order to fully capture the interest and passion of their members and sustain social impact.

\section{ACKNOWLEDGEMENT}

This research was supported by the Social Sciences and Humanities Research Council of Canada.

\section{ORCID}

Katie Misener (iD https://orcid.org/0000-0002-6132-2092

\section{REFERENCES}

Aguinis, H., \& Glavas, A. (2012). What we know and don't know about corporate social responsibility: A review and research agenda. Journal of Management, 38(4), 932-968.

Andreini, D., Pedeliento, G., \& Signori, S. (2014). CSR and service quality in nonprofit organizations: The case of a performing arts association. International Journal of Nonprofit and Voluntary Sector Marketing, 19(2), 127-142.

Babiak, K., \& Wolfe, R. (2013). Perspectives on CSR in sport. In J. L. Paramio, K. Babiak, \& G. Walters (Eds.), The handbook of corporate responsibility in sport: Principles and practice (pp. 17-34). London, England: Routledge.

Bhattacharya, C. B., \& Sen, S. (2004). Doing better at doing good: When, why, and how consumers respond to corporate social initiatives. California Management Review, 47(1), 9-24.

Bruner, G. C., Hensel, P. J., \& James, K. E. (2005). Marketing scales handbook, 4: Consumer behavior. Chicago, IL: South-Western Educational and Professional.

Carroll, A. (1979). A three-dimensional conceptual model of corporate performance. Academy of Management Review, 4, 497-505.

Carroll, A. (1999). Corporate social responsibility: Evolution of a definitional construct. Business \& Society, 38, 268-295.

Cuskelly, G., Taylor, T., Hoye, R., \& Darcy, S. (2006). The relationship between volunteer management practices and volunteer retention in community sport organisations. Sport Management Review, 9(2), 141-163.

Diddi, S., \& Niehm, L. S. (2016). Corporate social responsibility in the retail apparel context: Exploring consumers' personal and normative influences on patronage intentions. Journal of Marketing Channels, 23(1-2), 60-76.

Dillman, D. A. (2007). Mail and internet surveys: The tailored design method (2nd ed.). Hoboken, NJ: Wiley \& Sons.

Doherty, A. (2005). Volunteer management in community sport clubs: A study of volunteers' perceptions. Toronto, Ontario, Canada: Parks and Recreation Ontario.

Doherty, A., \& Misener, K. (2008). Community sport networks. In M. Nicholson \& R. Hoye (Eds.), Sport and social capital (pp. 113-141). London, England: Elsevier Butterworth-Heinemann.

Doherty, A., Misener, K., \& Cuskelly, G. (2014). Toward a multidimensional framework of capacity in community sport clubs. Nonprofit and Voluntary Sector Quarterly, 43(2), 124S-142S.

Doherty, A., Patterson, M., \& Van Bussel, M. (2004). What do we expect? An examination of perceived committee norms in non-profit sport organisations. Sport Management Review, 7(2), 109-132. 
Du, S., Bhattacharya, C. B., \& Sen, S. (2007). Reaping relational rewards from corporate social responsibility: The role of competitive positioning. International Journal Research in Marketing, 24(3), 224-241.

Du, S., Bhattacharya, C. B., \& Sen, S. (2010). Maximizing business returns to corporate social responsibility (CSR): The role of CSR communication. International Journal of Management Reviews, 12(1), 8-19.

Funk, D. C., \& James, J. D. (2004). The FAN attitude network (FAN) model: Exploring attitude formation and change among sport consumers. Sport Management Review, 7(1), 1-26.

Gross, H., \& Rottler, M. (2018). Nonprofits' internal marketing and its influence on volunteers' experiences and behavior: A multiple mediation analysis. Nonprofit and Voluntary Sector Quarterly, 48(2), 388-416.

Gruen, T. W., Summers, J. O., \& Acito, F. (2000). Relationship marketing activities, commitment, and membership behaviors in professional associations. Journal of Marketing, 64(3), 34-49.

Hager, M. A., Juaneda-Ayensa, E., Nogueira, F., Pstross, M., \& Smith, D. (2016). Member acquisition and retention in associations. In The Palgrave handbook of volunteering, civic participation, and nonprofit associations (pp. 975-991). London, England: Palgrave Macmillan.

Hager, M. A. (2013). Gathering information from nonprofits: Towards representative survey samples. Journal of Nonprofit Education and Leadership, 3(1), 47-59.

Hager, M. A. (2014). Engagement motivations in professional associations. Nonprofit and Voluntary Sector Quarterly, 43(2S), 39-60.

Hall, M. H., de Wit, M. L., Lasby, D., McIver, D., Evers, T., Johnston, C., ... Murray, V. (2005). Cornerstones of community: Highlights from the National Survey of nonprofit and voluntary organizations. Ottawa, Ontario, Canada: Minister of Industry.

Hoye, R. (2007). Commitment, involvement and performance of voluntary sport organization board members. European Sport Management Quarterly, 7(1), 109-121.

Kim, J. W., James, J. D., \& Kim, Y. K. (2013). A model of the relationship among sport consumer motives, spectator commitment, and behavioral intentions. Sport Management Review, 16(2), 173-185.

Kline, R. B. (2011). Principles and practice of structural equation modelling (3rd ed.). New York, NY: Guilford Press.

Kumar, A., Lee, H., \& Kim, Y. (2009). Indian consumers' purchase intention toward a United States versus local brand. Journal of Business Research, 62(5), 521-527.

Lee, S. P., \& Babiak, K. (2017). Measured societal value and its impact on donations and perception of corporate social responsibility: An experimental approach. Nonprofit and Voluntary Sector Quarterly, 46(5), 1030-1051.

Lee, Y., Kim, M., \& Koo, J. (2016). The impact of social interaction and team member exchange on sport event volunteer management. Sport Management Review, 19(5), 550-562.

Lichtenstein, D. R., Drumwright, M. E., \& Braig, B. M. (2004). The effect of corporate social responsibility on customer donations to corporate-supported nonprofits. Journal of Marketing, 68(4), 16-32.

Lin-Hi, N., Hörisch, J., \& Blumberg, I. (2015). Does CSR matter for nonprofit organizations? Testing the link between CSR performance and trustworthiness in the nonprofit versus for-profit domain. Voluntas: International Journal of Voluntary and Nonprofit Organizations, 26(5), 1944-1974.

Misener, K., \& Babiak, K. (2015). A new 'arena': Social responsibility through community sport. Paper presented at the Conference of the North American Society for Sport Management Conference (NASSM), Ottawa, Ontario, Canada.

Morris, K. (2013). Can non-profit organizations be good social citizens? Journal of Professional Communication, $3(1), 159-180$.

Morrison, K. A., Misener, K. E., \& Mock, S. E. (2018). The influence of corporate social responsibility and team identification on spectator behavior in major junior hockey. Leisure Sciences. https://doi.org/10.1080/ 01490400.2017.1408511

Morsing, M., \& Schultz, M. (2006). Corporate social responsibility communication: Stakeholder information, response and involvement strategies. Business Ethics: A European Review, 15(4), 323-338.

Muthén, L. K., \& Muthén, B. O. (1998-2012). Mplus user's guide (5th ed.). Los Angeles, CA: Muthén \& Muthén.

Nichols, G., Taylor, P., James, M., Holmes, K., King, L., \& Garrett, R. (2005). Pressures on the UK voluntary sport sector. Voluntas: International Journal of Voluntary and Nonprofit Organizations, 16(1), 33-50.

Paswan, A. K., \& Troy, L. C. (2004). Non-profit organization and membership motivation: An exploration in the museum industry. Journal of Marketing Theory and Practice, 12(2), 1-15. 
Persson, H. (2008). Social capital and social responsibility in Denmark: More than gaining public trust. International Review for the Sociology of Sport, 43(1), 35-51.

Pope, S., Bromley, P., Lim, A., \& Meyer, J. W. (2018). The pyramid of nonprofit responsibility: The institutionalization of organizational responsibility across sectors. VOLUNTAS: International Journal of Voluntary and Nonprofit Organizations, 29(6), 1300-1314.

Pressgrove, G. N., \& McKeever, B. W. (2016). Nonprofit relationship management: Extending the organizationpublic relationship to loyalty and behaviors. Journal of Public Relations Research, 28(3-4), $193-211$.

Ringuet-Riot, C., Cuskelly, G., Auld, C., \& Zakus, D. H. (2014). Volunteer roles, involvement and commitment in voluntary sport organizations: Evidence of core and peripheral volunteers. Sport in Society, 17(1), $116-133$.

Robertson, J., Eime, R., \& Westerbeek, H. (2018). Community sports clubs: Are they only about playing sport, or do they have broader health promotion and social responsibilities? Annals of Leisure Research, 22(2), 215-232.

Ross, J. K., Stutts, M. A., \& Patterson, L. T. (1990). Tactical considerations for the effectiveness of cause related marketing. The Journal of Applied Business Research, 7(2), 58-65.

Sen, S., Bhattacharya, C., \& Korschun, D. (2006). The role of corporate social responsibility in strengthening multiple stakeholder relationships: A field experiment. Journal of the Academy of Marketing Science, 34(2), $158-166$.

Sharpe, E. K. (2006). Resources at the grassroots of recreation: Organizational capacity and quality of experience in a community sport organization. Leisure Sciences, 28(4), 385-401.

Sinha, M. (2015). Volunteering in Canada, 2004 to 2013. (Catalogue no. 89-652-X2015003). Ottawa, Ontario, Canada: Statistics Canada. Retrieved from https://www150.statcan.gc.ca/n1/pub/89-652-x/89-652-x2015003eng.htm

Skinner, J., Zakus, D., \& Cowell, J. (2008). Development through sport: Building social capital in disadvantaged communities. Sport Management Review, 11(3), 253-275.

Sotiriadou, P., \& Wicker, P. (2013). Community sports clubs' responses to institutional and resource dependence pressures for government grants. Annals of Leisure Research, 16(4), 297-314.

Thomas, M., Mullen, L., \& Fraedrich, J. (2011). Increased word-of-mouth via strategic cause-related marketing. International Journal of Nonprofit and Voluntary Sector Marketing, 16, 36-49.

Tidwell, M. V. (2005). A social identity model of prosocial behaviors within nonprofit organizations. Nonprofit Management and Leadership, 15(4), 449-467.

Tonts, M. (2005). Competitive sport and social capital in rural Australia. Journal of Rural Studies, 21(2), 137-149.

True Sport Foundation. (2016). Sport and belonging, 2016 vital signs report. Retrieved from http:// communityfoundations.ca/wp-content/uploads/2016/04/Vital_Signs_Sport_and_Belonging.pdf

Tschirhart, M., \& Gazley, B. (2014). Advancing scholarship on membership associations: New research and next steps. Nonprofit and Voluntary Sector Quarterly, 43(2S), 3S-17S.

Vidal, P., Torres, D., Guix, B., \& Rodríguez, M. P. (2005). The social responsibility of non-profit organisations: A conceptual approach and development of SRO model. Barcelona, Spain: Observatori del Tercer Sector.

Walker, M., \& Heere, B. (2011). Consumer attitudes toward responsible entities in sport (CARES): Scale development and model testing. Sport Management Review, 14(2), 153-166.

Walker, M., \& Kent, A. (2013). The roles of credibility and social consciousness in the corporate philanthropyconsumer behavior relationship. Journal of Business Ethics, 116(2), 341-353.

Waters, R. D., \& Ott, H. K. (2014). Corporate social responsibility and the nonprofit sector: Assessing the thoughts and practices across three nonprofit subsectors. Public Relations Journal, 8(3), 1-18.

Webster, F. E. (1975). Determining the characteristics of the socially conscious consumer. Journal of Consumer Research, 2(3), 188-199.

Weyzig, F. (2009). Political and economic arguments for corporate social responsibility: Analysis and a proposition regarding the CSR agenda. Journal of Business Ethics, 86(4), 417-428.

Wicker, P., \& Breuer, C. (2011). Scarcity of resources in German non-profit sport clubs. Sport Management Review, 14(2), 188-201.

Williams, M., \& Buttle, F. (2013). Managing word-of-mouth: A nonprofit case study. Journal of Nonprofit and Public Sector Marketing, 25(3), 284-308. 
Zajonc, R. B. (2001). Mere exposure: A gateway to the subliminal. American Journal of Psychology, 56(6-7), 522-523.

Zeimers, G., Anagnostopoulos, C., Zintz, T., \& Willem, A. (2019). Examining collaboration among nonprofit organizations for social responsibility programs. Nonprofit and Voluntary Sector Review, 48(5), 953-974.

\section{AUTHOR BIOGRAPHY}

Katie Misener is an Associate Professor in the Department of Recreation and Leisure Studies, University of Waterloo. Her research focuses on the capacity and social impact of nonprofit community sport organizations, with an emphasis on how capacity can be enhanced to support sport service delivery and foster social engagement through sport.

Kristen Morrison is a PhD candidate in the Department of Recreation and Leisure Studies, University of Waterloo. Her research focuses on the development and use of organizational strategy by non-profit sport organizations, with an emphasis on how strategy may be used to achieve desirable outcomes, such as membership growth.

Micheal L. Shier is an Associate Professor at the Factor-Inwentash Faculty of Social Work, University of Toronto. His research interests include social innovation and social entrepreneurship, human service nonprofits, and social policy and social welfare development.

Kathy Babiak is an Associate Professor in Sport Management, University of Michigan. Her main line of research focuses on the interorganizational partnerships in sport organizations, with a focus on strategic alliances or philanthropic interactions.

How to cite this article: Misener K, Morrison K, Shier M, Babiak K. The influence of organizational social responsibility on involvement behavior in community sport membership associations. Nonprofit Management and Leadership. 2020;30:591-611. https://doi.org/10.1002/nml.21406 